University of Nebraska - Lincoln

DigitalCommons@University of Nebraska - Lincoln

\title{
Morpho-physiological parameters affecting iron deficiency chlorosis in soybean (Glycine max L.)
}

\author{
Marta W. Vasconcelos \\ USDA-ARS Children's Nutrition Research Center, mvasconcelos@porto.ucp.pt \\ Michael A. Grusak \\ USDA-ARS Children's Nutrition Research Center, mike.grusak@ars.usda.gov
}

Follow this and additional works at: https://digitalcommons.unl.edu/usdaarsfacpub

Vasconcelos, Marta W. and Grusak, Michael A., "Morpho-physiological parameters affecting iron deficiency chlorosis in soybean (Glycine max L.)" (2013). Publications from USDA-ARS / UNL Faculty. 1302.

https://digitalcommons.unl.edu/usdaarsfacpub/1302

This Article is brought to you for free and open access by the U.S. Department of Agriculture: Agricultural Research Service, Lincoln, Nebraska at DigitalCommons@University of Nebraska - Lincoln. It has been accepted for inclusion in Publications from USDA-ARS / UNL Faculty by an authorized administrator of DigitalCommons@University of Nebraska - Lincoln. 


\title{
Morpho-physiological parameters affecting iron deficiency chlorosis in soybean (Glycine $\max \mathbf{L}$.)
}

\author{
Marta W. Vasconcelos • Michael A. Grusak
}

This article is a U.S. government work, and is not subject to copyright in the United States.

Received: 4 February 2013 / Accepted: 10 July 2013

(C) Springer Science+Business Media B.V. (outside the USA) 2013

\begin{abstract}
Background and aims Iron deficiency chlorosis (IDC) leads to severe leaf chlorosis, low photosynthetic rates, and yield reductions of several million metric tonnes each year. In order to devise breeding and genetic transformation programs that aim at generating high-yielding and IDC-tolerant soybean lines, it is necessary to better understand the mechanisms that enable tolerant plants to survive under Fe-limiting conditions.

Methods An in silico analysis in the USDA soybean collection allowed the identification of a set of novel efficient and inefficient soybean cultivars which can be used in future studies concerning IDC response. Plants were grown in iron deficient and iron sufficient conditions using a bicarbonate system and several IDCrelated aspects were studied.

Results A new set of efficient and inefficient soybean lines were identified in silico, and their tolerance to IDC was confirmed under laboratorial conditions. New plant traits that are highly correlated to IDC scoring were identified: a negative correlation was found between SPAD values and stem weight, weight of the unifoliolates
\end{abstract}

Responsible Editor: Jian Feng Ma

M. W. Vasconcelos $(\bowtie) \cdot$ M. A. Grusak

USDA-ARS Children's Nutrition Research Center, Baylor

College of Medicine,

Houston, TX 77030, USA

e-mail: mvasconcelos@porto.ucp.pt

Present Address:

M. W. Vasconcelos

CBQF - Centro de Biotecnologia e Química

Fina-Laboratório Associado, Escola Superior de

Biotecnologia, Universidade Católica Portuguesa/Porto,

Rua Dr. António Bernardino Almeida,

4200-072 Porto, Portugal and iron concentration of the first unifoliolates was found; higher SPAD values were correlated with the amount of iron in the first trifoliate leaves. Our data also show that having higher concentrations of iron in the seeds provides increased resistance to IDC. No correlation was found between root iron reductase activity and chlorosis.

Conclusions Soybean differential chlorosis susceptibility between different accessions is linked to specific morpho-physiological parameters such as unifoliolate leaf size, stem weigh, concentration of iron in the seeds, and tissue iron partitioning.

Keywords IDC · Iron ·

Reductase $\cdot$ Soybean $\cdot$ Trifoliate $\cdot$ Unifoliolate

\section{Introduction}

The legumes have been consumed by humans since the earliest practice of agriculture and have been used both for their medicinal, cultural as well as nutritional properties, providing an important source of protein and oil, which can also be converted into biodiesel (Libault et al. 2010). Legumes and cereals are the two most important plant foods to humans (Graham and Vance 2003). Soybean (Glycine max L.) is the highest produced legume crop. In fact, the Food and Agriculture Organization statistics for 2009 (http://faostat.fao.org/site/339/default. aspx) show that about 230 million metric tons of soybean were produced across the world, ranking 8th on the world's top commodity production.

Iron plays an important role in general plant metabolism: it is required for photosynthesis, respiration, nitrogen fixation, DNA synthesis, hormone production, 
chlorophyll formation and it is a component of various redox and iron-sulphur enzymes (Zheng 2010). Even though iron exists in fairly high concentrations in the soil, it is very often unavailable for uptake, leading to a phenomenon termed iron deficiency chlorosis (IDC). IDC is generally associated with calcareous, high $\mathrm{pH}$ soils, because under these conditions the Fe in the soils is less available for uptake. Other factors that seem to be associated with IDC are low temperature, high relative humidity and high nitrate concentrations in the soil. Why these conditions seem to worsen the IDC response is not yet clear. It is estimated that in the USA, IDC reduces total soybean production by several million metric tonnes each year (Naeve and Rehm 2006). While IDC affects principally soybean production, it also occurs with other plants.

Plants affected by IDC show yellowing of the upper leaves, interveinal chlorosis and stunted growth. As a consequence, the plant's yield is severely affected. SPAD values are an indirect measurement of chlorophyll concentration based on the transmission of red light (at $650 \mathrm{~nm}$ ) and the transmission of infrared light (at $940 \mathrm{~nm}$ ) through a leaf sample. Higher SPAD values indicate a lower degree of leaf chlorosis. SPAD has been used before as a good indicator of chlorophyll concentration and degree of chlorosis (Markwell et al. 1995; Richardson et al. 2001; Richardson and Berlyn 2002; Uddling et al. 2007). Besides impacting chlorophyll synthesis, IDC also lowers the concentrations of iron in the seeds and other harvested tissues (Grusak 1999). Thus, it impacts both farmer profit and the nutritional value of plant products.

It has been suggested before that seed Fe concentration may influence the plants ability to survive in iron limiting soils (Karkosh et al. 1988). In fact, one of the management practices used to address IDC is direct application of iron to the seeds (Karkosh et al. 1988; Pioneer 2009).

Even though much has been learned about the physiology of iron uptake in model species, there is no clear understanding of the physiology of tolerance to iron deficiency in soybean, and this has hampered breeding programs. Plants have been classified as 'Fe-efficient' (EF) if they respond to Fe deficiency stress by inducing biochemical reactions that make Fe available in a useful form and 'Fe-inefficient' (INF) if they do not (Brown 1978). Cultivar selection is the most common measure for avoiding IDC in plants; therefore it is important to establish quick and reliable screening tools.
Soybean utilizes the strategy I mechanism of Fe uptake, which consists in increasing the activity of a root iron reductase in order to convert the less soluble ferric iron $\left(\mathrm{Fe}^{3+}\right)$ to the more soluble ferrous iron $\left(\mathrm{Fe}^{2+}\right)$ (Römheld and Marschner 1986). Ferric reducing capacity is often increased in plants suffering from iron deficiency (Romera et al. 1992; Cinelli et al. 1995; Romera and Alcántara 2004; Blair et al. 2010) and physiological studies in pea show that the reduction of ferric iron is the rate limiting process for iron acquisition (Grusak et al. 1990). In fact, soybean (Vasconcelos et al. 2006) and tobacco ( $\mathrm{Li}$ et al. 2011) constitutively expressing an iron reductase from Arabidopsis thaliana showed enhanced reductase activities and had higher tolerance to IDC. However, more recent work conducted in Lotus japonicus suggests that an increase in root ferric reductase activity is important, but it is not the only factor contributing to a plant's ability to minimize IDC (Klein et al. 2012). Also, Alcántara et al. (2000) suggests that the $\mathrm{Fe}^{3+}$ root reducing activity is not always related to Fe chlorosis tolerance. Other physiological parameters are involved in the process, such as root subapical swelling with abundant root hairs, rhizosphere acidification, ethylene production (Romera and Alcántara 2004), organic acid release (Abadía et al. 2002), or even the activity of the enzyme phosphoenolpyruvate carboxylase (De Nisi and Zocchi 2000).

Traditional strategies to alleviate IDC-caused yield losses include soil amendment and foliar iron sprays (Schenkeveld et al. 2010), especially to correct mild chlorosis. However, this is not economically feasible. For this reason, the most commonly used strategy is still to choose IDC efficient lines. Attempts have been made with success to generate molecular makers such as SSRs (Charlson et al. 2003; Charlson et al. 2005; Lin et al. 1997; Wang et al. 2008) and RFLPs (Lin et al. 1997; Lin et al. 2000) for IDC tolerance. These, in theory, can be very effective at identifying IDC-tolerant lines within breeding populations. Other lines of research have aimed at identifying QTLs that explain the variation of the iron chlorosis trait (Diers et al. 1992; Kassem et al. 2006), identifying soybean genes (Rogers et al. 2009) and transcription factors (Peiffer et al. 2012) which are involved in Fe uptake or creating transgenic soybean plants with increased tolerance to IDC (Vasconcelos et al. 2006).

Soybean is a good model crop to study IDC because 1) it is an economically important agricultural crop; 2) cultivars with differential IDC susceptibility are available; 3 ) 
similarly to Arabidopsis thaliana, it has a wealth of genomic information readily available (Schmutz et al. 2010).

Despite all the efforts being made in the last decades to develop a solution for this lingering agricultural problem, at present, no cultivar has complete tolerance to IDC. In this study, we present novel traits found in soybean plants that are correlated with the iron efficiency trait. These can be useful as additional tools in breeding programs aiming at selecting IDC tolerant genotypes. We describe a set of experiments designed to detect associations between different physiological and plant nutritional aspects and iron deficiency chlorosis in soybean.

\section{Materials and methods}

Plant material

Because IDC is so variable within cultivars and under different environmental conditions (Naeve and Rehm 2006), 32 cultivars with differential IDC response were obtained from the USDA germplasm collection via GRIN (http://www.ars-grin.gov/). In order to identify those cultivars with differential IDC susceptibility, cultivars were searched in the "Soybase and The Soybean Breeder's Toolbox" (http://soybase.org/) and in GRIN using chlorosis as the environmental stress descriptor. Eight independent studies were found in the database. In GRIN, a scoring of $1.0=$ 'no chlorosis' up to $5.0=$ 'severe chlorosis' was given to all cultivars in the studies. This rating system is essentially identical to that used by Lin et al. (1997) and Wang et al. (2008). Because variety screening based on IDC scores requires multiple locations to be accurate (Naeve and Rehm 2006), two different criteria to label an accession were utilized in the current study: 1) cultivars had to be scored for chlorosis in at least 4 separate studies, and 2) the cultivars had to show average chlorosis values of $\leq 2.4$ or $\geq 3.9$ to be labelled as $\mathrm{EF}$ or INF, respectively (Table 1). Under these criteria $16 \mathrm{EF}$ and 16 INF cultivars were identified (Fig. 1).

Additionally, in this work, the EF soybean line (U00-424033), generated at University of NebraskaLincoln for increased tolerance to IDC, was used. The EF transgenic line 392-3, over-expressing an iron reductase gene from Arabidopsis thaliana and used previously in IDC studies as a tolerant line, as well as its wild type INF counterpart Thorne were also utilized (Vasconcelos et al. 2006).
Hydroponic conditions for confirmation of IDC response

Plants were grown for 2 weeks in a climate chamber with 16-h, $20^{\circ} \mathrm{C}$-day and 8-h, $15^{\circ} \mathrm{C}$-night. Relative humidity was maintained at $50 \%$ and photon flux density during the day was $350 \mu \mathrm{mol} \mathrm{m} \mathrm{m}^{-2} \mathrm{~s}^{-1}$, supplied by a mixture of incandescent bulbs and fluorescent lamps. Seeds were first nicked with a razor blade to facilitate seed imbibition and germinated in flaks with wet filter paper for 5 days before being transferred to hydroponic solution with different $\mathrm{Fe}$ treatments. Plants were grown for IDC assessment using a modification of the Chaney et al. (1972) method. In short, germinated seedlings were grown in 4-hole black buckets containing $4.5 \mathrm{~L}$ of either Fe-sufficient (high $\mathrm{Fe}$ ) or Fe-deficient (low $\mathrm{Fe}$ ) hydroponic solution prepared according to the recipe outlined by Chaney et al. (1992). Nutrient solution contained air enriched with $3 \% \mathrm{CO}_{2}$ for aeration and stabilization of the $\mathrm{pH}$. The $\mathrm{pH}$ of the Fe-sufficient condition was 6.0 , and the $\mathrm{pH}$ of the Fe-deficient condition was 7.5, until the end of the experiment (at 14 days). The solution was replaced every 2 days and the $\mathrm{pH}$ was checked at the end of the experimental period. The low Fe and high Fe solutions were prepared with the iron chelator DTPA (diethylenetriamine pentaacetic acid) and contained $25 \mu \mathrm{M}$ Fe-DTPA/20 mM $\mathrm{NaHCO}_{3}$ or $50 \mu \mathrm{M} \mathrm{Fe}-$ DPTA/10 $\mathrm{mM} \mathrm{NaHCO}$, respectively.

\section{Scoring for IDC tolerance}

In order to confirm the our in silico identification of the Efficient (EF) or Inefficient (INF) accessions obtained from the USDA germplasm, a subset of twelve accessions grown in the Fe-deficient conditions described above were assessed at V1 stage of development-the day that the first trifoliate leaves are fully emerged and open (Fehr and Caviness 1979). SPAD readings (Minolta, USA) were performed in the 1st trifoliate leaves, at four consecutive days. The readings were done in triplicate and using 4 plants per accession. IDC tolerance was also assessed with SPAD in a subset of lines grown in iron deficient and iron sufficient conditions that were used to study the effect of iron reductase activity (please see below the protocol for iron reductase activity), and to study the correlation between SPAD and Fe and $\mathrm{Zn}$ concentration and plant organ weight. 
Table 1 Summary of the data obtained from GRIN (http://www.ars-grin.gov/cgi-bin/npgs/html/eval.pl?492949) after conducting an in silico search for soybean chlorosis scoring. Six locations, all in the sate of Minnesota (MN) were studied in the years 1963,2001 and 2004. The author of the study, as well as the year the study was preformed, the number of accessions that were observed in each study, and the minimum, maximum and average chlorosis score obtained at each experimental site is included in the table

\begin{tabular}{|c|c|c|c|c|c|c|}
\hline \multirow[t]{2}{*}{ Study locations } & \multirow[t]{2}{*}{ Author(s) } & \multicolumn{3}{|c|}{ Chlorosis score } & \multirow[t]{2}{*}{ Year } & \multirow[t]{2}{*}{ \# Accessions } \\
\hline & & Min. & Max. & Avg. & & \\
\hline Morgan, MN & Scott, L. (unp.) & 1.0 & 5.0 & 3.4 & 2001 & 1094 \\
\hline Boyd, MN & Scott, L. (unp.) & 1.0 & 5.0 & 2.9 & 2001 & 1341 \\
\hline Buffalo Lake, MN & Scott, L. (unp.) & 1.0 & 5.0 & 3.4 & 2004 & 373 \\
\hline Morgan, MN & Scott, L. (unp.) & 2.4 & 5.0 & 4.4 & 2004 & 386 \\
\hline Morgan, MN & Scott, L. (unp.) & 1.6 & 5.0 & 3.5 & 2004 & 386 \\
\hline Sleepy Eye, MN & Scott, L. (unp.) & 1.0 & 3.7 & 1.2 & 2004 & 385 \\
\hline Wood Lake, MN & Scott, L. (unp.) & 1.1 & 4.5 & 2.7 & 2004 & 386 \\
\hline MN (Latitude: $45^{\circ} 00$ Minutes N Longitude: $93^{\circ} 07$ Minutes W) & Bernard et al. 1998 & 1.0 & 5.0 & 2.5 & 1963 & 287 \\
\hline Total \# of observations & & & & & & 4638 \\
\hline
\end{tabular}

Dry weight and tissue elemental analysis

Seventy plants belonging to 18 different lines were used to study the correlation between SPAD and Fe and $\mathrm{Zn}$ concentrations and DWs of different plant organs. Tissues were harvested and dried overnight in a $60{ }^{\circ} \mathrm{C}$ oven. Samples were weighed, digested overnight in borosilicate glass tubes by adding $4 \mathrm{ml}$ of redistilled $98.8 \% \mathrm{HNO}_{3}$ and $1 \mathrm{ml}$ of concentrated trace metal grade $\mathrm{HClO}_{4}$. Samples were heated at $100{ }^{\circ} \mathrm{C}$ for

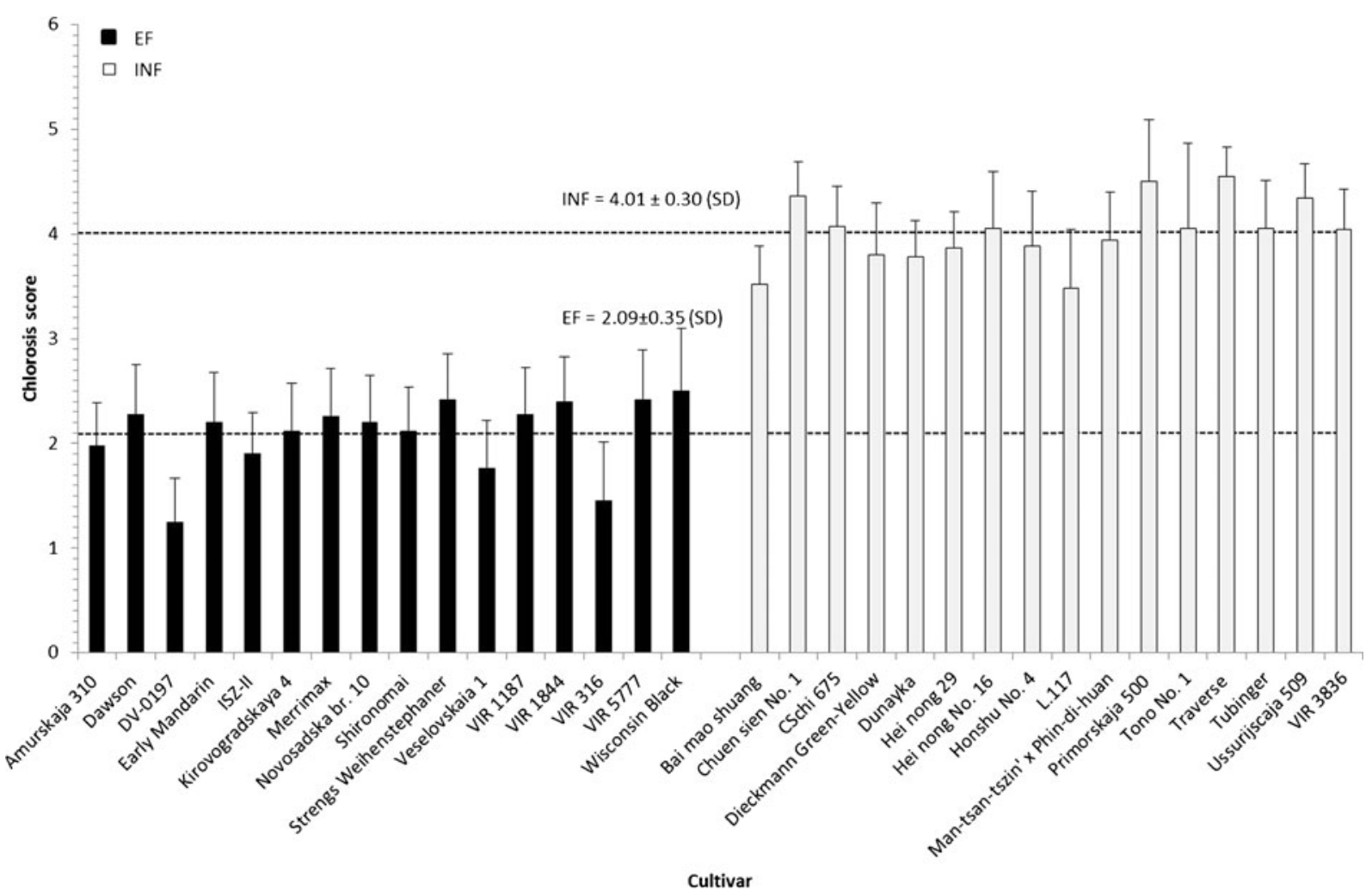

Fig. 1 Efficient (dark bars) and inefficient (white bars) soybean cultivars identified using in silico analysis. Additional characteristics for these cultivars can be found in GRIN (http://www.ars-grin.gov/) 
$1 \mathrm{~h}, 150{ }^{\circ} \mathrm{C}$ for $1 \mathrm{~h}, 180^{\circ} \mathrm{C}$ for $1 \frac{1}{2} \mathrm{~h}$ and then at $210^{\circ} \mathrm{C}$ to dryness. Digestions were performed using a heating block (Model 1016, Tecator, Höganäs, Sweden) with an exhaust-collecting manifold. Digests were resuspended in $15 \mathrm{ml}$ of redistilled $2 \% \mathrm{HNO}_{3}$. Elemental analysis was performed using inductively coupled plasma spectroscopy (ICP-OES) at Baylor College of Medicine, Children's Nutrition Research Center, Houston, TX, USA. Five plants were grown for each treatment as described before. Material from each plant was ground and five independent digestions were performed prior to ICP-OES analysis. For the individual seed analysis, intact seeds (not grinded) were used for digestion.

\section{Root iron reductase}

Three EF and 3 INF cultivars grown hydroponically using the screening protocol described before (Chaney et al. 1992), were used for reductase activity measurement using the protocol optimized before for soybean (Vasconcelos et al. 2006). Specifically, freshly excised roots were rinsed in a modified nutrient solution $[1.2 \mathrm{mM}$ $\mathrm{KNO}_{3}, 0.8 \mathrm{mM} \mathrm{Ca}\left(\mathrm{NO}_{3}\right)_{2}, 0.3 \mathrm{mM} \mathrm{NH}_{4} \mathrm{H}_{2} \mathrm{PO}_{4}, 0.2 \mathrm{mM}$ $\mathrm{MgSO}_{4}$ ] then placed in approximately $200 \mathrm{~mL}$ of a continuously aerated assay solution $\left[1.2 \mathrm{mM} \mathrm{KNO}_{3}\right.$, $0.8 \mathrm{mM} \mathrm{Ca}\left(\mathrm{NO}_{3}\right)_{2}, 0.3 \mathrm{mM} \mathrm{NH} \mathrm{H}_{2} \mathrm{PO}_{4}, 0.2 \mathrm{mM}$ $\mathrm{MgSO}_{4}, 1 \mathrm{mM}$ MES at pH 5.5, $0.1 \mathrm{mM}$ Fe(III)-EDTA, and $0.1 \mathrm{mM}$ bathophenanthroline disulfonic acid (BPDS)]. Exact assay volume was measured prior to the start of the assay. The assay was run under very low light conditions for $45 \mathrm{~min}$, an aliquot of the assay solution was then removed and $\mathrm{A}_{535}$ was measured spectrophotometrically. An aliquot of assay solution not exposed to roots was used as a blank. Root fresh weight was measured at assay completion. $\mathrm{Fe}(\mathrm{II})-\mathrm{BPDS}_{3}$ concentration was calculated using the extinction coefficient of $22.14 \mathrm{mM}^{-1} \mathrm{~cm}^{-1}$. As a control, the possible contribution of soluble reductants released from roots to overall root iron reduction was assessed. Roots were placed for $30 \mathrm{~min}$ in buffered nutrient solution with no iron source or BPDS, and aliquots of the solutions were collected prior to transferring the roots to regular assay solution for 30 min supplemented with $100 \mu \mathrm{M}$ Fe(III)-EDTA and $100 \mu \mathrm{M}$ BPDS. An aliquot of the solution from each root system collected prior to iron addition was added to a solution containing $100 \mu \mathrm{M}$ Fe(III)-EDTA and $100 \mu \mathrm{M}$ BPDS and left for $30 \mathrm{~min}$; absorbance was then read at $535 \mathrm{~nm}$ as described above.
Statistical analysis

Welch's $t$-test and ANOVA linear regression analysis were used to compare the seed Fe concentration with SPAD values. A Pearson's linear correlation analysis was performed to determine the correlation between SPAD values measured in the first trifoliate leaves, weight of different plant parts, $\mathrm{Fe}$ concentration of different plant parts, $\mathrm{Fe}$ and $\mathrm{Zn}$ remobilization from the cotyledons and total $\mathrm{Fe}$ in the different plant parts. All data analyses were performed using SPSS version 9.0 (SPSS, Inc., Chicago IL).

\section{Results}

IDC scoring of plant material

From the in silico analysis performed using the methodology described in the Materials and Methods section, $16 \mathrm{EF}$ and $16 \mathrm{INF}$ cultivars were identified (Fig. 1). The INF lines had a composite average chlorosis score of $4.1 \pm 0.2(\mathrm{SD})$ and the efficient ones had a score of $2.1 \pm 0.3$ (SD).

To confirm whether the in silico analysis identified varieties that would also behave similarly under hydroponic conditions, a subset of cultivars- 6 EF lines, 6 INF lines, ( 5 cultivars from GRIN and the control line Thorne)-were grown and the average 1st trifoliate SPAD values were measured at four consecutive days (Fig. 2). It was found that the lines that had shown higher IDC tolerance in the field also showed higher SPAD values when grown in laboratorial Fe-limiting conditions (Fig. 1 and 2). For instance, cultivars Kirovogradskaya 4, Veselovskaia 1 and VIR 1187, which had been categorized as EF in the in silico analysis, also showed the highest SPAD values in the trifoliates over the four consecutive days when grown hydroponically. The variety Thorne, which is considered INF, was used as a control, and it showed low values of SPAD when compared to the EF cultivars obtained from the USDA germplasm collection. Cultivar Hei nong No. 16, an INF line in the field trials analysis, had also the lowest SPAD values in hydroponic conditions $[14.5 \pm 1.3$ (SD) on day 1 lowering to $5.7 \pm 1.3$ (SD) on day 4]. Cultivar L.117, also categorized as INF (Fig. 1), showed high SPAD values at the first day of measurement, but had an abrupt decrease in SPAD readings from D1 to D2, ending up at D4 with one of the lowest SPAD values. 


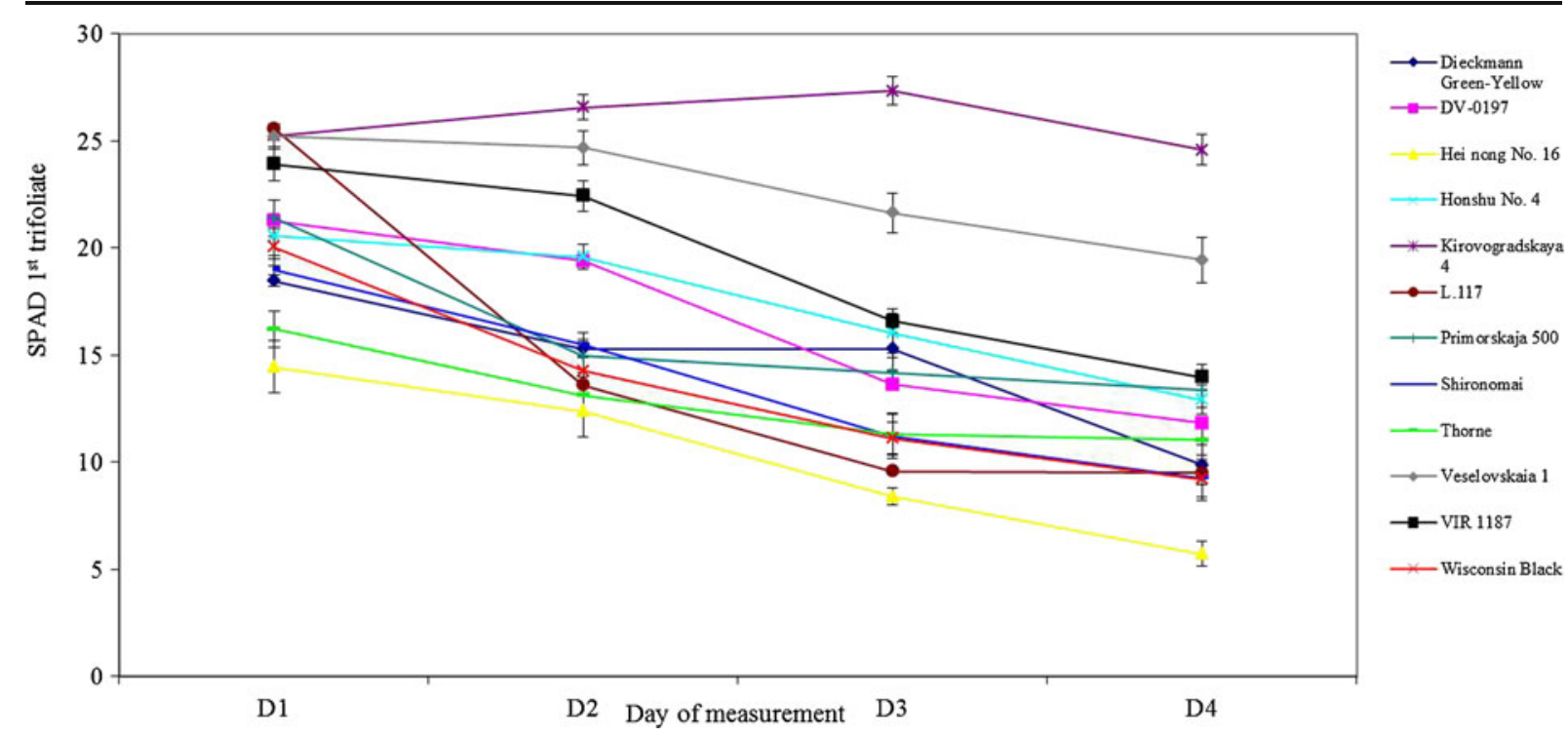

Fig. 2 Confirmation of IDC status as Efficient (EF) or Inefficient (INF), under laboratorial conditions. Average 1st trifoliate SPAD values measured in 12 different soybean cultivars obtained from the USDA germplasm collection at four consecutive days. Plants

\section{Organ weight IDC scoring}

When analysing the potential contribution of individual plant organ DW (cotyledon, unifoliolate, root, stem and trifoliate) to the IDC susceptibility (SPAD values measured in the first trifoliate leaves), a significant negative correlation between SPAD index with unifoliolate and stem DW was found (Table 2). The correlation coefficient for SPAD values relative to the DW of the first true leaves was $-0.40(p=0.0005$, Fig. 4 and Table 2), and for stem DW it was $-0,25(p<0,05)$. This suggests that plants which have heavier first unifoliolate leaves have higher IDC susceptibility. Contrarily, there was a positive correlation between trifoliate DW and IDC, but this was not statistically proven (data not shown). Also, cotyledon and root DW were not linked with higher IDC tolerance.

\section{Micronutrient concentration and IDC efficiency}

Assessing the contribution of tissue Fe concentration to IDC susceptibility, it was found that Fe concentration in the unifoliolates was negatively correlated to SPAD, with a coefficient of $-0,25$ ( $p<0.05$; Table 2$)$, suggesting that higher remobilization of $\mathrm{Fe}$ to the unifoliolate leaves negatively impacts SPAD indexes. Contrarily, the concentration of $\mathrm{Fe}$ in the trifoliate leaves was positively were grown hydroponically in Fe deficient conditions. The first date of measurement was at V1 stage of development - the day that the first trifoliate leaves are fully emerged and open (Fehr and Caviness 1979)

correlated with SPAD with a coefficient of 0,29 $(p<0.05$; Table 2), which indicates that having higher $\mathrm{Fe}$ concentrations in the trifoliate is related to higher SPAD values.

No significant correlation was found between SPAD values and the percentage of iron or zinc remobilized from the cotyledons, or with the total amount of iron in the cotyledons. There was, however, a positive correlation between the concentration of cotyledonal $\mathrm{Fe}$ with the concentration of $\mathrm{Fe}$ in the unifoliolates and in the roots.

Table 2 gives us additional data that may be indirectly related to the observed SPAD values. For example, it was found that root biomass was positively correlated to $\mathrm{Fe}$ concentrations in the trifoliate leaves, in the roots, and in the unifoliolates, with correlation coefficients of $0.39(p<0.01), 0.42(p<0.001)$ and 0.49 $(p<0.001)$, respectively. Also, it seems that $\mathrm{Fe}$ and $\mathrm{Zn}$ remobilization are positively correlated with each other (0.46 with $p<0.001)$. Also, Table 2 indicates that the heavier cotyledons are associated with heavier unifoliolates, roots, stems and trifoliate leaves, which is demonstrated by the highly significant positive correlation between these variables (Table 2). This observation reenforces the importance of the cotyledons in nutrient and carbohydrate remobilization to the germinating plant. 


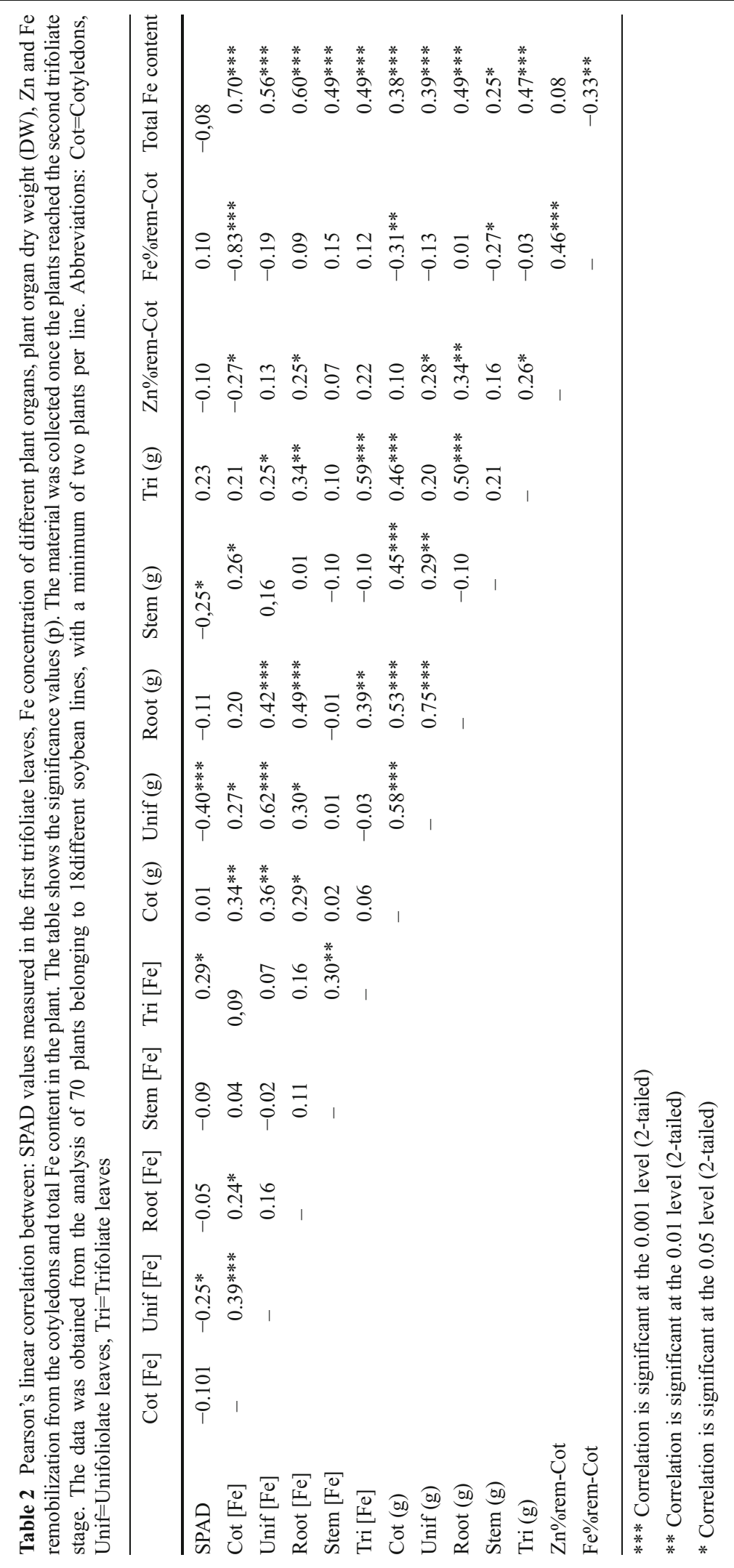




\section{Seed Fe concentration and IDC efficiency}

Previous studies have suggested that seed Fe concentration may influence the plants ability to survive in iron limiting soils (Karkosh et al. 1988). In order to test this hypothesis, ICP analysis was conducted on the seeds of the 32 cultivars which were categorized as EF or INF, as well as on the lines EF lines U00-424033, 392-3 and INF line Thorne, comparing Fe concentration in the seeds with IDC efficiency. The seed Fe concentration was averaged for all the EF lines, as well as for the INF lines, and a Tukey comparison was made. It was found that seed $\mathrm{Fe}$ concentration was significantly different between the EF lines and the INF lines, with the later having lower average seed Fe concentrations of about $20 \%$ (Fig. 3, and 4).

\section{Root Fe reductase activity and IDC tolerance}

Root $\mathrm{Fe}$ reductase activity was measured in plants grown in the presence of bicarbonate, in order to simulate calcareous soil conditions (Chaney et al. 1992). A survey of ferric reductase activity using a subset of Glycine max cultivars of differential IDC susceptibility (inefficient lines Primorskaja 500 and Dieckmann Green-Yellow, efficient line DV-0197, efficient transgenic line 392-3 and line U00424033) showed no statistically significant differences in whole root ferric reductase activity between cultivars (Fig. 5a). All cultivars showed higher reductase activities when grown in high $\mathrm{Fe}$ conditions (low bicarbonate) than when grown in low $\mathrm{Fe}$ concentrations (high bicarbonate). In

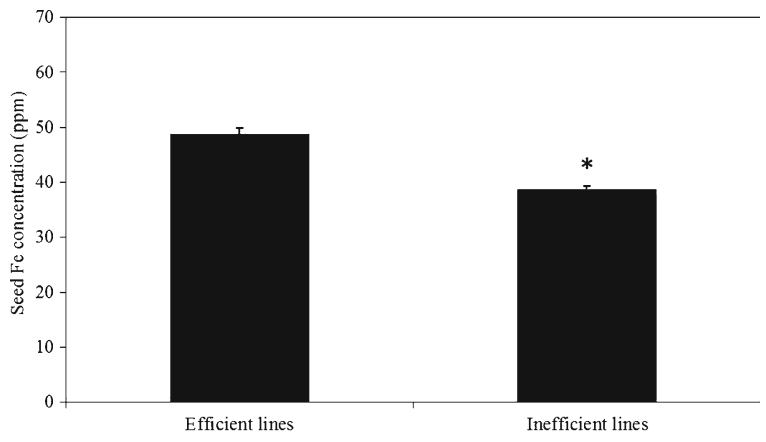

Fig. 3 Seed Fe concentration vs. SPAD values in a set of $16 \mathrm{EF}$ and 16 INF soybean lines. The values for seed concentration were averaged and a Welch's $t$-test was used to compare the Fe concentration in the seeds with the efficiency trait. The material analysed was obtained from the USDA germplasm collection via GRIN (http://www.ars-grin.gov/). The two-tailed P value was 0.0324

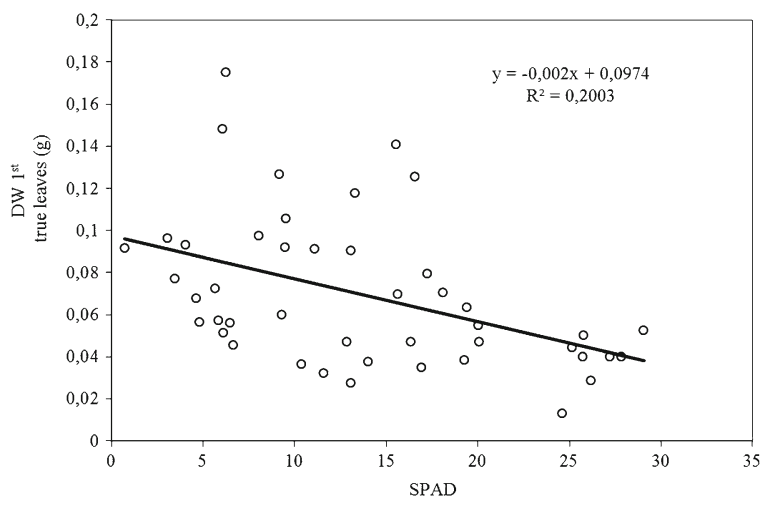

Fig. 4 Dry weight of the unifoliolates (first true leaves) vs. SPAD values in a set of $16 \mathrm{EF}$ and 16 INF soybean lines. A Welch's $t$-test was used to compare the dry weight of the unifoliolates with the iron efficiency trait. The two-tailed $\mathrm{P}$ value was 0.0324 , considered significant

high Fe concentrations, cultivar DV-0197 showed the highest reductase activity, whereas line Primorskaja 500 showed the lowest (Fig. 5a). On Fe deficient conditions, also DV-0197 showed the highest reductase activity levels.

When looking at SPAD values, it can be seen that there was variability in the SPAD values of the $1 \mathrm{st}$ trifoliates when plants were grown under high or low Fe conditions (Fig. 5b). The line showing highest SPAD values both in iron deficiency and sufficiency was U00424033, concordant to its status as a line bred specifically for iron efficiency. The highly susceptible line Dieckmann Green-Yellow, which had already shown low SPAD values in laboratory (Fig. 2) and field conditions (Fig. 1) showed the lowest SPAD values in the first trifoliate leaves, both in high and low iron conditions (Fig. 5b). The remaining lines showed intermediate SPAD reading values. In this study, no correlation was found between SPAD values relative to root Fe reductase activity (data not shown).

\section{Discussion}

Iron deficiency chlorosis is known to reduce yield of soybeans even though no visual indication of iron chlorosis can be observed (O'Rourke et al. 2007). Under strict criteria we were able to designate 16 cultivars as efficient and 16 cultivars as inefficient after being tested using hydroponic conditions that create low iron availability similar to calcareous soils (Fig. 1 and 2). This set of lines can be useful in future studies 
Fig. 5 Root iron reductase activity (a) and SPAD values (b) in a set of Glycine max cultivars of differential IDC susceptibility (inefficient lines Thorne, Primorskaja 500 and Dieckmann Green-Yellow; efficient lines 00-424033, DV-0197 and 392-3). Plants were grown in Fe deficient and $\mathrm{Fe}$ sufficient conditions using a hydroponic method that simulated calcareous soil conditions (Chaney et al. 1992).

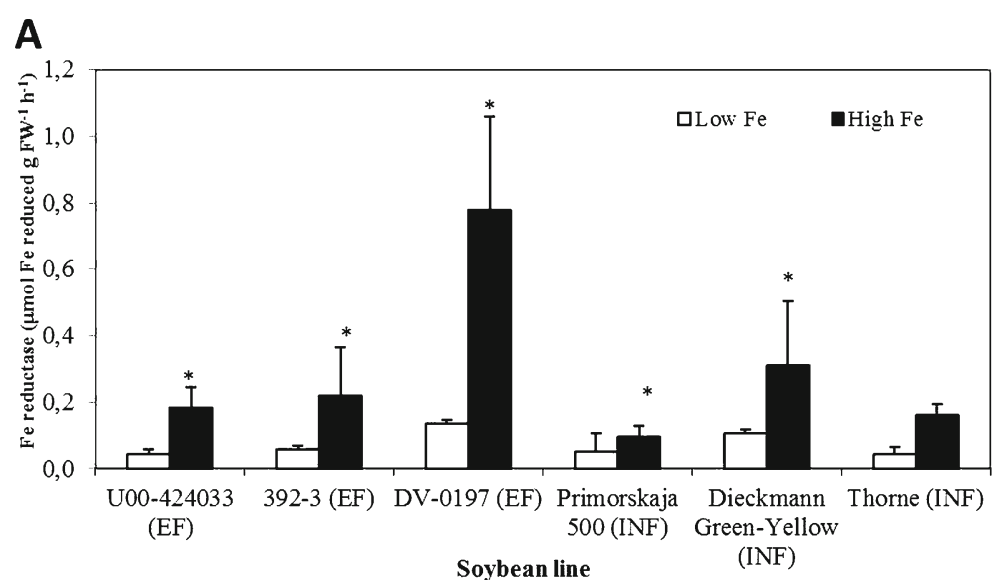

\section{B}

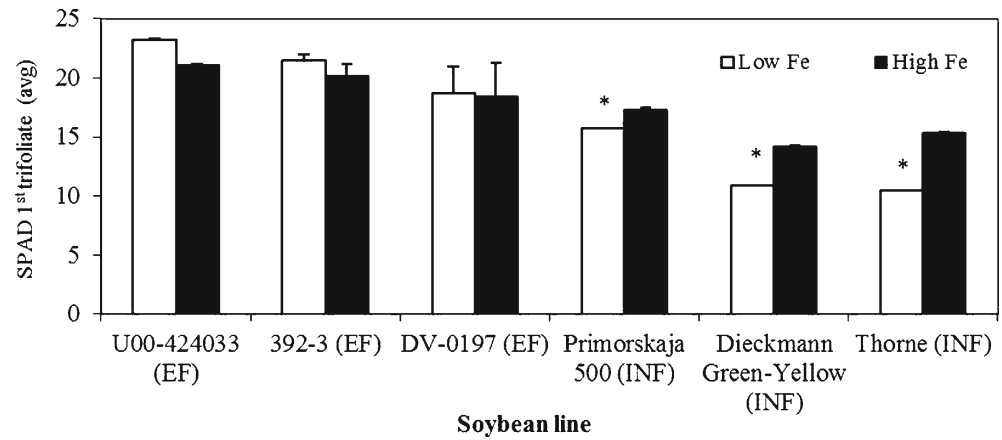

of IDC in soybean, as they seem to behave consistently as EF or INF regardless of location or environmental conditions.

In our studies using these 32 lines, we found a positive correlation between seed concentration of iron and higher SPAD values, which indicates that having higher seed iron levels may improve IDC response (Fig. 3). As soybean plants mainly take up Fe from the roots in the progressed vegetative and in the reproductive stages (Schenkeveld et al. 2010), our data indicates that at an early development stage, the seed storage of iron is important in the chlorosis response. In fact, one of the management practices used to address IDC is application of iron to the seeds (Karkosh et al. 1988; Godsey et al. 2003; Pioneer 2009). During the early stages of development, soybean cotyledons supply the nutrient needs of the young plant for about seven to 10 days (McWilliams et al. 2004). The cotyledon stage in soybean begins when the unifoliolate leaves are fully expanded (McWilliams et al. 2004). When looking at the role of cotyledonar $\mathrm{Fe}$, we did not find a correlation between the total $\mathrm{Fe}$ remobilized from the cotyledons and SPAD. We did find, however, a positive correlation between cotyledon Fe and unifoliate and root $\mathrm{Fe}$ (Table 2), suggesting that these two plant organs are the major recipients of Fe remobilized from the cotyledons.

When looking at the contribution of plant organ weight to IDC susceptibility, a significant negative correlation between SPAD values with unifoliolate and stem weight was found (Table 2). This observation has never been reported before. It has been shown that efficient soybean plants generally are the shortest (Elmstrom and Howard 1969), suggesting a negative correlation between stem length and IDC tolerance. Perhaps the large amounts of Fe being channelled to bigger unifoliolate leaves impair the Fe that is left for remobilization to the trifoliates, which are emerging after the unifoliolates. This hypothesis is substantiated by the observation that $\mathrm{Fe}$ concentration in the unifoliolates was negatively correlated to SPAD, with a coefficient of -0.25 ( $p<0.05$; Table 2$)$.

Gruber and Kosegarten (2002) showed that suppressed leaf formation and poor leaf growth are typical symptoms of IDC response, due to the high sensitivity of the meristematic apex to low iron availability. In the current study, 
the correlation between higher SPAD values and lower weight of unifoliolates and stems could be related to the differential sensitivity of the meristem apexes in these soybean lines. Contrarily, $\mathrm{Fe}$ in the trifoliate leaves was positively correlated with SPAD scoring (Table 2), which indicates that having higher $\mathrm{Fe}$ concentrations in the trifoliates is related to higher IDC tolerance. This is expected, as iron is required for chlorophyll formation and photosynthesis (Zheng 2010).

Plants with higher Fe concentrations in the trifoliate leaves, roots, and unifoliolates showed significantly higher root biomasses. It is likely that higher root biomass, and consequently higher absorbable surface area, may lead to higher intake of iron that can be stored in those tissues.

The lack of iron is one of the more common nutrients associated with chlorosis. However, zinc deficiencies in the soybean plant will also cause chlorosis (Elmstrom and Howard 1969; Sliman and Motto 1990). When looking at $\mathrm{Zn}$ cotyledon concentration and remobilization, no significant correlation was found to SPAD values. However, it seems that $\mathrm{Fe}$ and $\mathrm{Zn}$ remobilization are positively correlated with each other $(0,46$ with $p<0.001)$, suggesting a common pathway for remobilization. This has been suggested before for sorghum (Brown and Jones 1977). Grain $\mathrm{Zn}$ and $\mathrm{Fe}$ concentrations were increased in barley (Hordeum vulgare) expressing the $\mathrm{Zn}$ transporter ZIP1 from Arabidopsis (Ramesh et al. 2004), and were decreased in wheat (Triticum aestivum) expressing RNAi constructs that lowered NAM family gene expression (Uauy et al. 2006). Moreover, Fang et al. (2008) showed that foliar application of $\mathrm{Zn}$ can influence the $\mathrm{Zn}$ but also the Fe content of rice grains, suggesting a common pathway of translocation.

Studies looking at root iron reduction capacity usually report that plants have higher reductase activity under Fe deficiency than under Fe sufficiency. This was not our observation (Fig. 5a). Reductase activity is highly dependent on the cultivar under study, on the type of Fe chelator used in the hydroponics system, and on pH (Lucena 2008; Blair et al. 2010). In fact, reductase activity of plant roots declines rapidly at high pH (Lucena 2008), and our Fe deficient solution, with bicarbonate, had a $\mathrm{pH}$ of 7.5 , whereas the Fe sufficient solution had a $\mathrm{pH}$ of 6.0 .

It has been observed that soybean EF plants, when grown under iron stress, usually develop the ability to absorb and translocate large quantities of iron, contrary to INF plants (Elmstrom and Howard 1969). Also, the roots of EF plants have a greater reducing capacity than INF plants (Brown et al. 1961; Brown and Jones 1962). In studies conducted with Lotus japonicus, a correlation was found between whole-root ferric reductase activity and SPAD readings following iron-limited growth (Klein et al. 2012). In our study, we did not find a correlation between $\mathrm{Fe}$ reductase activity and higher Fe efficiency (Fig. 5a and b), a phenomenon already observed by others (Alcántara et al. 2000). One explanation may be that soybean plant roots grown under the bicarbonate/Fe-DTPA system (Chaney et al. 1992) regulate the Fe reductase mechanism differently than in other hydroponic systems. In the studies conducted in Lotus, a different hydroponic system, using Fe-EDDHA as the iron chelator, were used (Brown et al. 1961), which could explain the differences. In fact, we have also seen that the same soybean accession when grown using the bicarbonate/Fe-DTPA or the Fe-EDDHA system shows different values of Fe reductase activity (data not shown). Further explanations could be the time-course variation of reductase activity after Fe withdrawal, which depends on species (Moog and Brüggemann 1994) or the ability to maintain the induction of the Fe reductase for long-enough periods (Tagliavini and Rombolà 2001).

Our lack of correlation between reducase activity and SPAD values could also be linked to the bicarbonate in the hydroponic solution, as it may have influenced the ability of the soybean plant to acidify the medium, and this is a crucial factor for generating available $\mathrm{Fe}^{2+}$. Tagliavini et al. (1995) have suggested that the presence of bicarbonate affects Fe reductase activity (Tagliavini et al. 1995). Also, Pissaloux et al. (1995) showed that in white lupine, bicarbonate and $\mathrm{pH}$ both have a decisive impact on the appearance of chlorosis symptoms, in particular in younger leaves, even at a $\mathrm{pH}$ of 7.5.

Tagliavini and Rombolà (2001) suggest that sustainable management of Fe nutrition should include all genetic and agronomical means in order to naturally enhance Fe availability in the soil and in the plant. Plant chlorosis induced by iron deficiency is a very variable trait that is affected not only by environmental conditions, but also by genetically determined factors, inherent to the cultivar itself. Farmers have been intuitively choosing certain soybean cultivars in detriment to others based on their visual chlorosis scoring in the field. However, the actual anatomical and biochemical aspects that make a certain line more IDC tolerant are still unknown. In this paper we have identified a novel set of EF soybean lines 
which can be used in future studies concerning IDC response. We have also identified plant traits that are highly correlated to IDC scoring, and that influence the plants ability to survive in iron limiting soils. Our findings suggest that IDC response is a complex mechanism that most likely involves a combination of factors that are genetically-inherited and anatomically-dependent.

Acknowledgments This work was funded in part by funds from USDA-ARS under agreement No. 58-6250-0-008 to

M.A.G. The authors would like to thank Tom Clemente for providing the 392-3 and U00-424033 soybean lines. The contents of this publication do not necessarily reflect the views or policies of the US Department of Agriculture, nor does mention of trade names, commercial products or organizations imply endorsement by the U.S. Government. The authors would also like to thank FCT for funding the project "IMPROVIRON: Improved Productivity and Iron Nutrition in Legume Grains" (PTDC/AGR-GPL/102861/2008).

\section{References}

Abadía J, López-Millán AF, Rombolà AD, Abadía A (2002) Organic acids and Fe deficiency: A review. Plant Soil 241:75-86

Alcántara E, Romera FJ, Canete M, de la Guardia MD (2000) Effects of bicarbonate and iron supply on $\mathrm{Fe}(\mathrm{III})$ reducing capacity of roots and leaf chlorosis of Fe susceptible peach rootstock 'Nemaguard'. J Plant Nutr 23:1607-1617

Bernard RL, Cremeens CR, Cooper RL, Collins FI, Krober OA, Athow KL, Laviolette FA, Coble CJ, Nelson RL (1998) Evaluation of the USDA soybean germplasm collection: Maturity groups 000-IV (FC 01.547-PI 266.807). USDA Technical Bulletin 1844:6-29

Blair MW, Knewtson SJB, Astudillo C, Li C-M, Fernandez AC, Grusak MA (2010) Variation and inheritance of iron reductase activity in the roots of common bean (Phaseolus vulgaris L.) and association with seed iron accumulation QTL. BMC Plant Biol 10:215

Brown JC (1978) Mechanism of iron uptake by plants. Plant Cell Environ 1:249-257

Brown JC, Holmes RS, Tiffin LO (1961) Iron chlorosis in soybeans as related to the genotype of rootstalk. Soil Sci 86:75-82

Brown JC, Jones WE (1962) Absorption of Fe, Mn, Zn, Ca, Rb, and phosphate ions by soybean roots that differ in their reductive capacity. Soil Sci 94:173-179

Brown JC, Jones WE (1977) Fitting plants nutritionally to soils. Agron J 69:410-414

Chaney RL, Brown JC, Tiffin LO (1972) Obligatory reduction of ferric chelates by soybeans. Plant Physiol 50:208-213

Chaney RL, Coulombe BA, Bell PF, Angle JS (1992) Detailed method to screen dicot cultivars for resistance to $\mathrm{Fe}$ chlorosis using FeDTPA and bicarbonate in nutrient solutions. J Plant Nutr 15:2063-2083

Charlson DV, Cianzio SR, Shoemaker RC (2003) Associating SSR markers with soybean resistance to iron deficiency chlorosis. J Plant Nutr 26:2267-2276
Charlson DV, Bailey TB, Cianzio SR, Shoemaker RC (2005) Molecular marker Satt481 is associated with iron-deficiency chlorosis resistance in a soybean breeding population. Crop Sci 45:2394-2399

Cinelli F, Viti R, Byrne DH, Reed DW (1995) Physiological characterization of two peach seedling rootstocks in bicarbonate nutrient solution. I. Root iron reduction and iron uptake. Dev Plant Soil Sci 59:323-328

De Nisi P, Zocchi G (2000) Phosphoenolpyruvate carboxylase in cucumber (Cucumis sati_us L.) roots under iron deficiency: Activity and kinetic characterization. J Exp Bot 51:19031909

Diers BW, Cianzio SR, Shoemaker RC (1992) Possible identification of quantitative trait loci affecting iron deficiency in soybean. J Plant Nut 15:2127-2136

Elmstrom GW, Howard FD (1969) Iron accumulation, root peroxidase activity, and varietal interactions in soybean genotypes that differ in iron nutrition. Plant Physiol 44:1108-1114

Fang Y, Wang L, Xin Z, Zhao L, An X, Hu Q (2008) Effect of foliar application of zinc, selenium, and iron fertilizers on nutrients concentration and yield of rice grain in china. $\mathrm{J}$ Agric Food Chem 56:2079-2084

Fehr WR, Caviness CE (1979) Stages of development. Cooperation extension service: Iowa state university 80:1-12

Godsey CB, Schmidt JP, Schlegel AJ, Taylor RK, Thompson CR, Gehrl RJ (2003) Correcting iron deficiency in corn with seed row-applied iron sulfate. Agron J 95:160-166

Graham PH, Vance CP (2003) Legumes: Importance and constraints to greater utilization. Plant Physiol 131:872-877

Gruber B, Kosegarten H (2002) Inhibited leaf growth of plants grown in alkaline solution and on calcareous soils is a more sensitive Fe-deficiency symptom than leaf chlorosis. In: Horst WJ, Schenk MK, Bürkert A, Claassen N, Flessa H, Frommer WB, Goldbach H, Olfs H-W, Römheld V, Sattelmacher B, Schmidhalter U, Schubert S, Wirén N, Wittenmayer L (eds) Developments in plant and soil sciences volume 92. Kluwer Academic Publishers, Dordrecht, pp 152-153

Grusak MA (1999) Genomics-assisted plant improvement to benefit human nutrition and health. Trends Plant Sci 4:164-166

Grusak MA, Welch RM, Kochian LV (1990) Does iron deficiency in pisum sativum enhance the activity of the root plasmalemma iron transport protein? Plant Physiol 94:13531357

Karkosh AE, Walker AK, Simmons JJ (1988) Seed treatment for control of iron deficiency chlorosis of soybean. Crop Sci 28:369-370

Kassem MA, Shultz J, Meksem K, Cho Y, Wood AJ, Iqbal MJ, Lightfoot DA (2006) An updated 'Essex' by 'Forrest' linkage map and first composite interval map of QTL underlying six soybean traits. Theor Appl Genet 113:1015-1026

Klein M, López-Míllan A, Grusak M (2012) Quantitative trait locus analysis of root ferric reductase activity and leaf chlorosis in the model legume, Lotus japonicus. Plant Soil 351:363-376

Libault M, Farmer A, Joshi T, Takahashi K, Langley RJ, Franklin LD, He J, Xu D, May G, Stacey G (2010) An integrated transcriptome atlas of the crop model Glycine max, and its use in comparative analyses in plants. Plant J 63:86-99 
Lin SL, Cianzio SR, Shoemaker RC (1997) Mapping genetic loci for iron deficiency chlorosis in soybean. Mol Breed 3:219229

Lin SL, Grant D, Cianzio SR, Shoemaker RC (2000) Molecular characterization of iron deficiency chlorosis in soybean. $\mathrm{J}$ Plant Nut 23:1929-1939

Li LY, Cai QY, Yu DS, Guo CH (2011) Overexpression of AtFRO6 in transgenic tobacco enhances ferric chelate reductase activity in leaves and increases tolerance to irondeficiency chlorosis. Mol Biol Rep 38:3605-3613

Lucena JJ (2008) Effects of bicarbonate, nitrate and other environmental factors on iron deficiency chlorosis. A review. J Plant Nutr 23:1591-1606

Markwell J, Osterman JC, Mitchell JL (1995) Calibration of the Minolta SPAD-502 leaf chlorophyll meter. Photosynth Res 46:467-472

McWilliams DA, Berglund DR, Endres GJ (2004) Soybean Growth and Management Quick Guide. In NDSU Agriculture and University Extension Educational Materials. pp 18. North Dakota State University and University of Minnesota, Fargo, ND

Moog PR, Brüggemann W (1994) Iron reductase systems on the plant plasma membrane: A review. Plant Soil 165:241-260

Naeve SL, Rehm GW (2006) Genotype x environment interactions within iron deficiency chlorosis-tolerant soybean genotypes. Agron J 98:808-814

O'Rourke JA, Graham MA, Vodkin L, Gonzalez DO, Cianzio SR, Shoemaker RC (2007) Recovering from iron deficiency chlorosis in near-isogenic soybeans: A microarray study. Plant Physiol Biochem 45:287-292

Peiffer GA, King KE, Severin AJ, May GD, Cianzio SR, Lin SF, Lauter NC, Shoemaker RC (2012) Identification of candidate genes underlying an iron efficiency quantitative trait locus in soybean. Plant Physiol 158:1745-54

Pioneer (2009) Management of Iron Deficiency Chlorosis of Soybeans. In Pioneer Technical Note. pp 1-2. Pioneer Agronomy Sciences Research, Iowa, USA.

Pissaloux A, Morard P, Bertoni G (1995) Alkalinity-bicarbonatecalcium effects on iron chlorosis in white lupine in soilless culture. In: Abadía J (ed) Iron nutrition in soils and plants. Developments in plant and soils sciences, vol. 59. Kluwer Academic Publishers, Dordrecht, pp 127-134

Ramesh SA, Choimes S, Schachtman DP (2004) Overexpression of an Arabidopsis zinc transporter in Hordeum vulgare increases short-term zinc uptake after zinc deprivation and seed zinc content. Plant Mol Biol 54:373-385

Richardson AD, Berlyn GP (2002) Changes in foliar spectral reflectance and chlorophyll fluorescence of four temperate species following branch cutting. Tree Physiol 22:499-506

Richardson AD, Duigan SP, Berlyn G (2001) An evaluation of non-invasive methods to estimate foliar chlorophyll content. New Phytol 153:185-194
Rogers EE, Wu X, Stacey G, Nguyen HT (2009) Two MATE proteins play a role in iron efficiency in soybean. J Plant Physiol 166:1453-1459

Romera FJ, Alcántara E (2004) Ethylene involvement in the regulation of Fe-deficiency stress responses by strategy I plants. Functional Plant Biol 31:315-328

Romera FJ, Alcántara E, De la Guardia MD (1992) The role of roots and shots in the regulation of the Fe deficiency responses in sunflower and cucumber. Physiol Plant 85:141-146

Römheld V, Marschner H (1986) Mobilization of iron in the rhizosphere of different plant species. Adv Plant Nutr 2:155-204

Schenkeveld WD, Reichwein AM, Bugter MH, Temminghoff EJ, van Riemsdijk WH (2010) Performance of soil-applied FeEDDHA isomers in delivering Fe to soybean plants in relation to the moment of application. J Agric Food Chem 58:12833-12839

Schmutz J, Cannon SB, Schlueter J, Ma J, Mitros T, Nelson W, Hyten DL, Song Q, Thelen JJ, Cheng J, Xu D, Hellsten U, May GD, Yu Y, Sakurai T, Umezawa T, Bhattacharyya MK, Sandhu D, Valliyodan B, Lindquist E, Peto M, Grant D, Shu S, Goodstein D, Barry K, Futrell-Griggs M, Abernathy B, Du J, Tian Z, Zhu L, Gill N, Joshi T, Libault M, Sethuraman A, Zhang XC, Shinozaki K, Nguyen HT, Wing RA, Cregan P, Specht J, Grimwood J, Rokhsar D, Stacey G, Shoemaker RC, Jackson SA (2010) Genome sequence of the palaeopolyploid soybean. Nature 463:178-183

Sliman ZT, Motto HL (1990) Differential response of Two soybean genotypes to zinc induced iron deficiency chlorosis. J King Saud Univ 2:71-80

Tagliavini M, Rombolà AD (2001) Iron deficiency and chlorosis in orchard and vineyard ecosystems. Eur J Agron 15:71-92

Tagliavini M, Rombolà AD, Marangoni B (1995) Response to iron-deficiency stress of pear and quince genotypes. J Plant Nutr 18:2465-2482

Uauy C, Distelfeld A, Fahima T, Blechl A, Dubcovsky J (2006) A NAC gene regulating senescence improves grain protein, zinc, and iron content in wheat. Science 314:1298-1301

Uddling J, Gelang-Alfredsson J, Piikki K, Pleije H (2007) Evaluating the relationship between leaf chlorophyll concentration and SPAD-502 chlorophyll meter readings. Photosynth Res 91:37-46

Vasconcelos M, Eckert H, Arahana V, Graef G, Grusak MA, Clemente T (2006) Molecular and phenotypic characterization of transgenic soybean expressing the Arabidopsis ferric chelate reductase gene, FRO2. Planta 224:1116-1128

Wang J, McClean PE, Lee R, Goos RJ, Helms T (2008) Association mapping of iron deficiency chlorosis loci in soybean (Glycine max L. Merr.) advanced breeding lines. Theor Appl Genet 116:777-787

Zheng SJ (2010) Iron homeostasis and iron acquisition in plants: maintenance, functions and consequences. Ann Bot 105:799-800 